Testing of a Loop Heat Pipe with Two Evaporators and Two Condensers

\author{
Jentung Ku \\ NASA Goddard Space Flight Center \\ Code 545 \\ Greenbelt, MD 20771 \\ (301)286-3130 \\ jentung.ku@gsfc.nasa.gov \\ Gaj Birur \\ Jet Propulsion Laboratory \\ Pasadena, CA
}

\begin{abstract}
Most existing LHPs consist of one single evaporator and one single condenser. LHPs with multiple evaporators will be very desirable for cooling multiple heat sources or a heat source with large thermal footprints. Extending the LHP technology to include multiple evaporators and multiple condensers faces some challenges, including the interaction between individual compensation chambers, operating temperature stability, and adaptability to rapid power and sink temperature transients. This paper describes extensive testing of an LHP with iwo evaporators and two condensers. Tests performed include start-up, power cycle, sink temperature cycle, reservoir temperature cycle, and capillary limit. Test results showed that the loop could operate successfully under various heat load and sink conditions. The loop operating temperature is a function of the total heat load, the heat load distribution between the two evaporators, and temperatures of the two condenser sinks. Under most conditions, only one reservoir contained two-phase fluid and the other reservoir was completely liquid filled. Moreover, control of the loop operating temperature could shift from one reservoir to the other as the test condition changed.
\end{abstract}

\title{
Introduction
}

Loop heat pipes (LHPs) are versatile heat transfer devices which have recently gained increasing acceptance for spacecraft thermal control. Most existing LHPs consist of one single evaporator and one single condenser. One of the major advantages offered by the LHP is its robust operation which stems from a specific physical construction. In LHP design, the evaporator and the compensation chamber form an integral part with a secondary wick connecting the two elements. The secondary wick can continuously draw liquid from the compensation chamber and the evaporator will always be replenished with liquid even when vapor bubbles are present inside the evapoiator core. Thus, the evaporator will not be vapor locked and dry out. However, the physical proximity of the evaporator and compensation does impose some constraints in the LHP operation. First, the temperature of the compensation chamber, which controls the loop operating temperature, is directly affected by the operating conditions such as the heat load, the condenser sink temperature and the ambient temperature. Second, the governing thermodynamic relation requires that the temperature difference between the evaporator ad the compensation chamber match the total system pressure drop minus the pressure drop across the primary wick. Third, minimization of the volume and weight, required by most spacecraft, places stringent requirements on the sizing of the compensation chamber and the fluid inventory. Thus, the evaporator and compensation chamber are usually designed for a specific loop, and are not easily adaptable when volumes of other components change significantly.

When multiple heat sources or a heat source with large thermal footprints needs to be cooled, an LHP with multiple evaporators will be very desirable. Extending the LHP technology to include multiple evaporators and multiple condensers faces some challenges. A simple thermodynamic analysis shows that, under most cases, only one of the compensation chambers will contains two-phase fluid and controls the loop operating temperature. All other compensation chambers will be completely filled. Therefore, there may be sizing limitations on the number of evaporators that can be integrated into a single loop. There are also operating issues that require further investigation, including the interaction between individual 
compensation chambers, operating temperature stability, and adaptability to rapid power and sink temperature transients. To help gain a better understanding of these issues, extensive tests were conducted on an LHP with two evaporators and two condensers. This paper presents a summary of the test results.

\section{Test Article}

As shown schematically in Figure 1, the test loop consists of two parallel evaporators, two parallel condensers, a common vapor transport line and a common liquid return line. Each evaporator has its own integral compensation chamber. Both evaporators are made of stainless steel tubing with $12.7 \mathrm{~mm}(0.5$ inch) O.D. by $76.2 \mathrm{~mm}$ (3 inches) length. One evaporator has a titanium wick with pore sizes of about 3 microns, while the other has a nickel wick with pore sizes about 1 micron. Both the vapor line and liquid line are made of $1.59 \mathrm{~mm}$ O.D. (1/16 inch) stainless steel tubing, and have a length of $1168 \mathrm{~mm}$ (46 inches). The vapor and liquid lines branch out to feed into the two evaporators and two condensers. Each condenser is made of $1.59 \mathrm{~mm}$ O.D.(1/16 inch) stainless steel tubing and is $508 \mathrm{~mm}$ (20 inches) long. A flow regulator made of capillary wicks is installed at the downstream of each condenser. The flow regulators prevent vapor from penetrating the wick before both condensers are fully utilized, and hence serve to balance the flows between the two condensers. Two $50.8 \mathrm{~mm}$ by $50.8 \mathrm{~mm}$ ( 2 inches by 2 inches) aluminum plate are installed on the vapor line. One is attached with an electrical heater while the other is attached with coolant lines. The two aluminum plates are used in the test to illustrate in a capillary system a small amount of heat load can be picked on the vapor line and dissipated to a nearby radiator. The loop is charged with 15.5 grams of anhydrous ammonia.

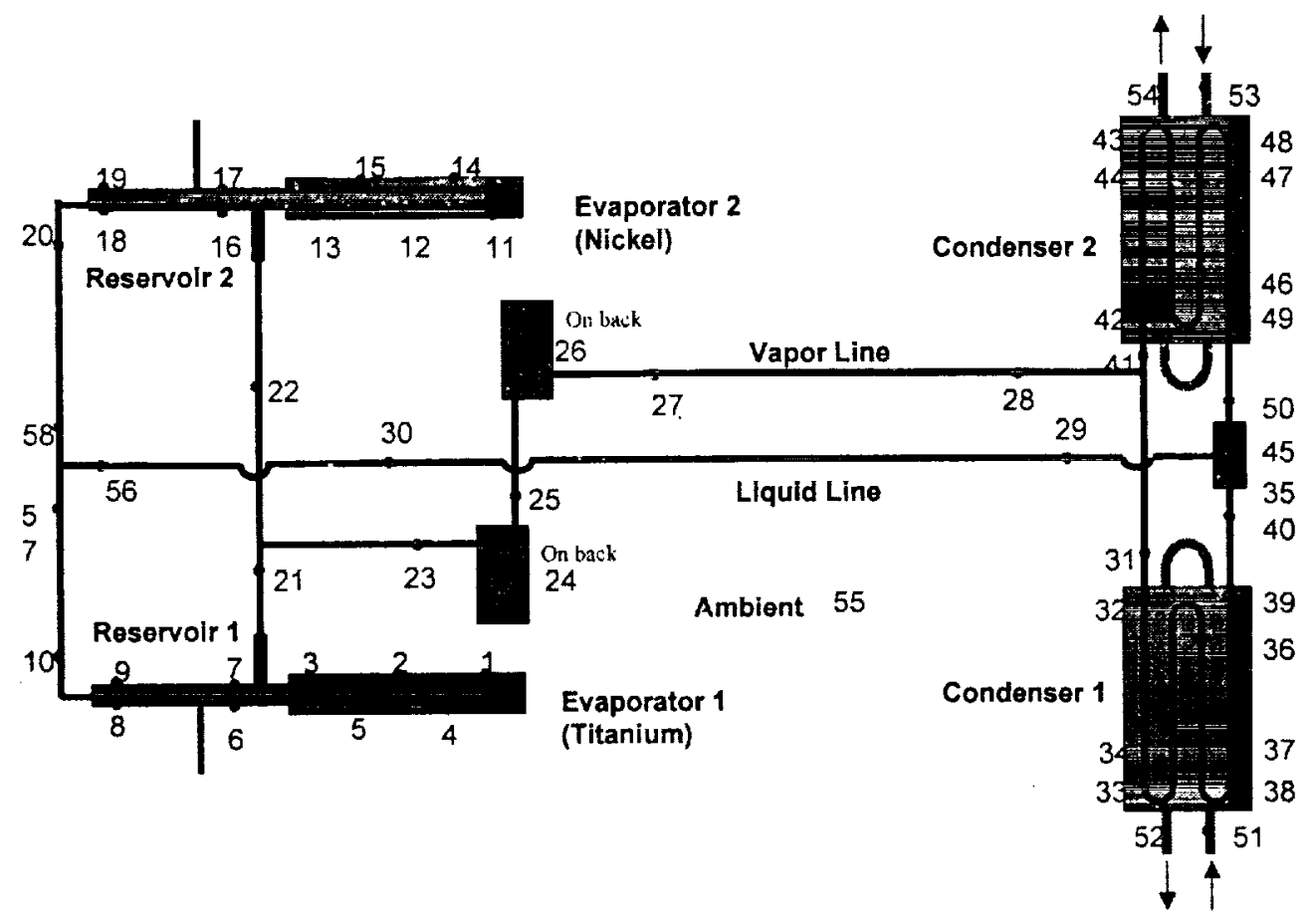

Figure 1. Schematic of an LHP with Two Evaporators and Two Condensers

Electrical heaters are attached to each evaporator and each compensation chamber, and are separately controlled. The two condensers are attached to two cold plates; each cooled by a separate chiller. Sixty thermocouples are used to monitor the loop temperatures. Notice that many thermocouples are installed on the liquid line between the two compensation chambers in order to monitor the anticipated interactions between the two elements during fast transients. A data acquisition system consisting of a datalogger, a personal computer, a CRT monitor, and Labview software programs is used to monitor and store data. The data is updated on the monitor and stored in the computer every second. 


\section{Tests Performed and Results}

Tests performed include start-up, power cycle, sink temperature cycle, high power, low power, and active control of the compensation chamber temperatures. Each type of test was performed with various heat loads to the two evaporators and different condenser sink temperatures. Lengthy steps and procedures were taken in order to gain insights on the physical processes involved in the loop operation when subjected to various conditions. The test program lasted for more than fifty days, collecting over 500 hours of test data. A summary of each test and the results is presented in the following sections. Details of different types of tests will be presented in separate papers.

For ease of description, the following aboreviations will be used: El=Evaporator 1 , $\mathrm{E} 2=$ Evaporaotr $2, \mathrm{Cl}=$ Condenser $1, \mathrm{C} 2=$ Condenser $2, \mathrm{CCl}=$ Compensation Chamber 1 , and $\mathrm{CC} 2=$ Compensation Chamber 2 . The terms compensation chamber and reservoir will be used interchangeably. Also, the test condition will be designated as (E1 power/E2 power, $\mathrm{Cl}$ sink temperature/C2 sink temperature). For example, $(5 \mathrm{~W} / 50 \mathrm{~W}, 273 \mathrm{~K} / 273 \mathrm{~K})$ means that $\mathrm{E} 1$ and $\mathrm{E} 2$ received $5 \mathrm{~W}$ and $50 \mathrm{~W}$ of heat loads, respectively, and both condenser sinks were set at $273 \mathrm{~K}$.

\section{$\underline{\text { Start-up }}$}

Start-up tests were conducted under a wide range of conditions, including various power levels, power distributions between the two evaporators, sink temperatures, and with or without pre-heating of the compensation chambers. Some start-up tests were conducted by applying the following heat load to one evapcrator only: $5 \mathrm{~W}, 25 \mathrm{~W}, 50 \mathrm{~W}, 75 \mathrm{~W}$ and $100 \mathrm{~W}$. Some start-ups were performed with the following heat loads to both evaporators: $5 \mathrm{~W} / 5 \mathrm{~W}, 5 \mathrm{~W} / 25 \mathrm{~W}, 25 \mathrm{~W} / 5 \mathrm{~W}, 10 \mathrm{~W} / 10 \mathrm{~W}, 5 \mathrm{~W} / 100 \mathrm{~W}, 100 \mathrm{~W} / 5 \mathrm{~W}, 25 \mathrm{~W} / 25 \mathrm{~W}$, $50 \mathrm{~W} / 50 \mathrm{~W}, 75 \mathrm{~W} / 25 \mathrm{~W}$, and $25 \mathrm{~W} / 75 \mathrm{~W}$. In some tests only one chiller was used, while in other tests both chillers were utilized and were set to the same or different temperatures ranging from $253 \mathrm{~K}$ to $299 \mathrm{~K}$.

Start-up is identified by a forward fluid flow in the loop, as indicated by an increase of the vapor line temperature to the saturation temperature and a decrease of the liquid line temperature. A start-up is considered successful if a forward fluid flow is established and the loop eventually reached a steady state. A total of 50 start-up tests were conducted and 48 were successful. In one of the two unsuccessful startups, a forward flow was established, but the compensation chamber temperature continued to rise above $323 \mathrm{~K}$ and there was no indication that a steady state was within reach even after more than 4 hours of operation. In the other unsuccessful start-up, a forward flow was never established. Furthermore, both unsuccessful start-ups had a heat load distribution of $5 \mathrm{~W} / 5 \mathrm{~W}$.

Figure 2 show the loop temperatures for the (50W/50W, $273 \mathrm{~K} / 273 \mathrm{~K})$ start-up. The loop started inmediately as indicated by an increased of the vapor line temperature TC23 and a decrease of the liquid line temperature TC30. . As will be discussed in details in the following section, the compensation chamber that has a higher temperature determines the loop operating temperature while the other compensation chamber will be flooded with liquid. In this case, the compensation chamber 1 temperature TC7 controlled the loop operating temperature and compensation chamber 2 was flooded with liquid. Figure 3 shows temperatures of the ( $5 \mathrm{~W} / 100 \mathrm{~W}, 273 \mathrm{~K} / 273 \mathrm{~K})$ start-up. Again, the loop started immediately after heat loads were applied to the evaporators. Note that, because evaporator 1 had a heat load of $5 \mathrm{~W}$ and evaporator 2 had a heat load of $100 \mathrm{~W}$, evaporator 1 temperature TC2 was lower than evaporator 2 temperature TC12, and evaporator 1 inlet temperature TC10 was higher than that of evaporator 2 inlet, TC20. The compensation chamber 1 temperature controlled the loop operating temperature. Figure 4 shows the loop temperatures in the $(100 \mathrm{~W} / 0 \mathrm{~W}, 273 \mathrm{~K} / 273 \mathrm{~K})$ start-up. In this case, the evaporator 2 had no heat load and acted as a condenser. The compensation chamber 2 temperature controlled the loop operating temperature as evidenced by the rise and fall of the vapor line and evaporator temperatures in tandem with compensation chamber 2 temperature $\mathrm{TC} 17$.

Figure 2. (50W/50W, $273 \mathrm{~K} / 273 \mathrm{~K}), 11 / 14 / 00,8: 30$ to $9: 30$. (done)

Figure 3. $(5 \mathrm{~W} / 100 \mathrm{~W}, 273 \mathrm{~K} / 273 \mathrm{~K}), 10 / 17 / 00,7: 30$ to $9: 30$.

Figure 4. (100W/0W, 273K/273K), 9/2 l/00, 8:30 to $9: 30$. 
Figure 5 shows that start-up when both compensation chamber temperatures were raised to $303 \mathrm{~K}$ prior to applying heat loads to the evaporators. Pre-heating of either or both of the compensation chambers always led to a backward fluid flow in all tests. This is evidenced by the rise of the liquid line temperatures TC10/TC20/TC56/TC30, and the fall of the vapor line temperature TC28 as shown in Figure 5. When the compensation chamber is heated, vapor was pushed into the evaporator core and then into the bayonet tube. The vapor flowed backward into the condenser. In other words, vapor was generated on the inner surface of the primary wicks. Meanwhile, the evaporator outer grooves were filled with liquid. The back flow would continue until a heat load was applied to the evaporator, which caused the liquid in the grooves to boil and establish a forward flow. Boiling of the liquid in the grooves, however, requires a certain amount of superheat. Not all of the heat load applied to the evaporator is used to boil the liquid because a small portion actually flows into the compensation chamber. In order to initiate nucleate boiling, the rate of temperature rise in the evaporator grooves must exceed that in the compensation chamber. The two unsuccessful start-ups had a heat load of $5 \mathrm{~W} / 5 \mathrm{~W}$. One of them had the compensation chambers preheated to $308 \mathrm{~K}$. Apparently, these low heat loads were not sufficient to establish the required superheat between the evaporator and the compensation chambers to initiate a forward flow.

Figure 5. (50W/50W, $273 \mathrm{~K} / 273 \mathrm{~K}$ ) with $\mathrm{CC} 1 / \mathrm{CC} 2$ control set at $303 \mathrm{~K}$ prior to start-up. (done, should change to $7: 45-8: 45) \mathrm{TC} 7,17,10,20,28,30,56, \mathrm{E} 1, \mathrm{E} 2$.

\section{Operation Without Active Control of CC Temperatures}

In an LHP with a single evaporator and a single condenser, the compensation chamber saturation temperature, which determines the loop operating temperature, is determined by an energy balance between the heat leak from the evaporator to the compensation chamber and the amount of liquid subcooling returning to the compensation chamber. Any factor that affects the energy balance will affect the compensation chamber temperature. Conversely, any factor that does not affect the energy balance will be isolated from and become "invisible" to the compensation chamber. The liquid subcooling is a function of the heat load, the sink temperature and the ambient temperature. The heat leak is a function of the heat load and the vapor void fraction inside the evaporator core. The latter is especially important at low heat loads. For an LHP with a fixed heat load and a fixed sink temperature, the evaporator core may have different vapor void fractions at different times. A higher void fraction will lead to a higher heat leak, which in turn result in a higher compensation chamber temperature. Thus, an LHP can operate at different temperatures under seeming identical conditions (i.e. the same heat load and sink temperature). This is the essence of the temperature hysteresis.

In an LHP with multiple evaporators and multiple condensers, the operating temperature become much more complex. A detailed discussion on this subject can be found in References 2 to 4 . Suffice it to say that it is very difficult for all compensation chambers to contain two-phase fluids in the same loop. Most likely, only one compensation chamber will have two-phase fluid and will control the loop operating temperature and all other compensation chambers will be completely filled with liquid. In order for all the compensation chambers to contain two-phase fluid, the following thermodynamic and hydrodynamic conditions must be satisfied:

1) The differential pressure and the differential temperature for each set of evaporator and compensation chamber must satisfy the Clausius-Clapeyron relation.

2) The differential pressure and the differential temperature between any two compensation chambers must also satisfy the Clausius-Clapeyron relation.

An equilibrium temperature can be reached for each compensation chamber based on the heat leak and liquid subcooling for that particular compensation chamber. Such an equilibrium temperature will almost inevitably different from those of the other compensation chambers. Since there can be only one operating temperature in the loop, the compensation chamber that has the higher equilibrium temperature will determine the loop operating temperature. This operating temperature is imposed upon all other compensation chambers, which will then have more liquid subcooling than required to compensate for the heat leak. Consequently, those compensation chambers will be completely filled with liquid. Moreover, 
which compensation chamber controls the loop operating temperature depends upon many factors, including the total heat load to the loop, the heat load distribution between the two evaporators, and the sink temperature. When more than one condenser is used, heat dissipating capability of each condenser, e.g. the sink temperature, is also a factor. In particular, control of the loop operating temperature can shift from one compensation chamber to the other as the heat load distribution changes even though the total heat load remain constant. Therefore, an LHP with multiple evaporators and multiple condensers will exhibit more temperature hystereses than an LHP with only a single evaporator and a single condenser.

In the test set-up shown in Figure 1, there are four thermocouples installed on each of the compensation chambers. In all tests, it was seen that the compensation chamber that controlled the loop operating temperature always showed a uniform temperature among all four thermocouples, while the compensation chamber that was flooded with liquid always showed divergent temperatures. One could determine which compensation chamber was in control by simply looking at the temperature distribution in both compensation chambers. Figure 6A showed the loop temperatures during the power cycle test of $100 \mathrm{~W} / 0 \mathrm{~W}, 75 \mathrm{~W} / 25 \mathrm{~W}, 50 \mathrm{~W} / 50 \mathrm{~W}, 25 \mathrm{~W} / 75 \mathrm{~W}, 0 \mathrm{~W} / 100 \mathrm{~W}, 100 \mathrm{~W} / 0 \mathrm{~W}, 100 \mathrm{~W} / 5 \mathrm{~W}, 5 \mathrm{~W} / 100 \mathrm{~W}$, and $0 \mathrm{~W} / 100 \mathrm{~W}$. Figures $6 \mathrm{~B}$ and $6 \mathrm{C}$ show the corresponding thermocouple temperatures of the $\mathrm{CCl}$ and $\mathrm{CC} 2$, respectively. As the heat load distribution varied between the two evaporators, control of the loop operating temperature shifted back and forth between the two ccmpensation chambers. With $100 \mathrm{~W}$ to El and no power to E2, E2/CC2 worked as a condenser and CC2 temperature determined the loop operating temperature. Moreover, since $\mathrm{E} 2 / \mathrm{CC} 2$ had to dissipate heat to ambient, its temperature could not be lower than the ambient temperature. Thus, the loop operating temperature was higher than the ambient temperature even though the both $\mathrm{Cl}$ and $\mathrm{C} 2$ sinks were at $273 \mathrm{~K}$ and were hardly fully utilized. The net heat to be dissipated by $\mathrm{E} 2 / \mathrm{CC} 1$ is, roughly speaking, determined by mass, momentum and energy balances among the three condensers $\mathrm{C} 1, \mathrm{C} 2$ and $\mathrm{E} 2 / \mathrm{CC} 2$. As E1/E2 heat loads changed to $75 \mathrm{~W} / 25 \mathrm{~W}$, control of the loop temperature quickly shifted to $\mathrm{CCl}$ as evidenced by the convergence of TC6 to TC 9 temperatures and the divergence of the TC16 to TC19 temperatures. Also note that with heat load to E2, the loop operating temperature dropped from $298 \mathrm{~K}$ to $293.5 \mathrm{~K}$. CCl remained in control of the loop operating temperature as E1/E2 heat loads changed to $50 \mathrm{~W} / 50 \mathrm{~W}$ and $25 \mathrm{~W} / 75 \mathrm{~W}$. However, the loop operating temperature increased with a decreasing E1 heat load even though the total hat load to the loop remained at $100 \mathrm{~W}$. This could be atributed to a decreasing liquid subcooling needed to balance the heat leak as E1 heat load decreased. At heat loads of $0 \mathrm{~W}: 100 \mathrm{~W}, \mathrm{E} 1 / \mathrm{CC} 1$ worked as a condenser and $\mathrm{CC} 1$ rose to a higher equilibrium temperature in order to dissipatc heat imposed from the vapor line.

The test shown in Figures $6 \mathrm{~A}, 6 \mathrm{~B}$ and $6 \mathrm{C}$ continued by switching E1/E2 heat loads from $0 \mathrm{~W} / 1 \mathrm{coW}$ to $100 \mathrm{~W} / 0 \mathrm{~W}$. As shown in the figures, control of the loop operating temperature shifted from $\mathrm{CCl}$ to $\mathrm{CC} 2$. At $100 \mathrm{~W} / 0 \mathrm{~W}$, the loop reached similar steady temperatures as those at the beginning of the test. However, during the transient, $\mathrm{CCl}$ temperature dropped rapidly from $299 \mathrm{~K}$ to $294 \mathrm{~K}$ and continued to control the loop operating temperature for 8 minutes. During this period, $\mathrm{CCl}$ contained two-phase fluid and $C$ C2 remained fully flooded with liquid. As heat was added to E2/CC2 from the vapor line, CC2 temperature gradually increased and suddenly generated vapor when the superheat was high enough. At the same time, vapor bubbles inside $\mathrm{CCl}$ were collapsed and $\mathrm{CCl}$ became fully flooded due to overwhelming liquid subcooling relative to the new saturation temperature of $298 \mathrm{~K}$ imposed by CC2. The head loads were then changed to $100 \mathrm{~W} / / 5 \mathrm{~W}$. Note that E2 switched from a condenser mode to an evaporator mode and the loop operating temperature increased to $303 \mathrm{~K}$. The role of E1/CCl and E2/CC2 switched again as EI/E2 heat loads changed from $100 \mathrm{~W} / 5 \mathrm{~W}$ to $5 \mathrm{~W} / 100 \mathrm{~W}$. The test ended with E/E2 heat loads of $0 \mathrm{~W} / 100 \mathrm{~W}$. The loop temperatures at $0 \mathrm{~W} / 100 \mathrm{~W}$ were similar to those seen under the same test conditions at 13:00. Notice that, between 13:30 and 18:30, how a small change of heat load from $0 \mathrm{~W}$ to $5 \mathrm{~W}$ (or vice versa) to one of the evaporators could change the loop operating temperature.

Figure 6. Shift of Operating Temperature Control During Power Cycle Test $6 \mathrm{~A}, 9 / 21 / 00,8: 30$ to $17: 00, \mathrm{TC} 7,17,2,12,28,10,20, \mathrm{EL}, \mathrm{E} 2$

$6 \mathrm{~B}, 9 / 21 / 00,8: 30$ to $17: 00, \mathrm{TC} 6,7,8,9, \mathrm{E} 1, \mathrm{E} 2$

$6 \mathrm{C}, 9 / 21 / 00,8: 30$ to $17: 00, \mathrm{TC} 6,7,8,9, \mathrm{E} 1, \mathrm{E} 2$ 
Figure 7 show the loop temperatures during the sirik temperature cycle test with E1/E2 heat loads of $50 \mathrm{~W} / 50 \mathrm{~W}$. The $\mathrm{Cl} / \mathrm{C} 2$ sink temperature varied as follows: $293 \mathrm{~K} / 29.3 \mathrm{~K} .293 \mathrm{~K} / 273 \mathrm{~K}, 273 \mathrm{~K} / 293 \mathrm{~K}$, $273 \mathrm{~K} 273 \mathrm{~K}, 273 \mathrm{~K} / 253 \mathrm{~K}, 253 \mathrm{~K} / 273 \mathrm{~K}$, and $253 \mathrm{~K} / 253 \mathrm{~K}$. In this test, CC 2 controlled the loop operating temperature throughout the test. Regardless how the sink temperatures changed, the liquids exiting from the two condensers merged and returned to the evaporator section. Since both evaporators had the same heat load, there are no sudden changes that might change the conditions within each compensation chamber. Thus, the compensation chamber that controlled the lcop operating temperature remained in control during the course of the test. In another identical sink temperature cycle test, $\mathrm{CCl}$ temperature controlied the loop the loop operating temperature when the loop started and remained in control throughout the test. This again illustrates that something drastic is necessary in order for the liquid-flooded compensation chambers to generate vapor and the two-phase compensation chamber to be liquid flooded at the same time.

Figure 7. Fixed heat loads $50 \mathrm{~W} / 50 \mathrm{~W}$, sink cycle, no shift in which $\mathrm{CC}$ controls the loop operating temperature. (Use 11/20/00 data frcm 9:30 to $15: 30, \mathrm{TC} 8,17,10,20,51,52, \mathrm{E} 1, \mathrm{E} 2$ )

Hysteresis. Same test condition, the other $\mathrm{CC}$ controlled the loop operating temperature throughout $11 / 20 / 00$ Start-up with $5 \mathrm{~W} / 100 \mathrm{~W}$, then $50 \mathrm{~W} / 50 \mathrm{~W}$ and sink cycle. CC2 in control throughout. $11 / 8 / 00$, Start-up with $50 \mathrm{~W} / 50 \mathrm{~W}, \mathrm{CCl}$ in control throughout.

In addition to what have been described above, the loop underwent some interesting transients during heat load changes and during low heat load operation. In particular, the liquid return line temperatures as indicated by TC10, TC20, TC56, TC57 and TC58 illustrated the interactions between the two evaporators and compensation chambers. A separate paper describes some fascinating phenomena during transients of loop operation [4].

\section{Active Control of CC Temperatures}

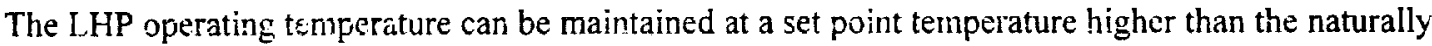
balanced temperature by heating one or both of the compensation clambers. When only one compensation chamber is actively controlled, the compensation chamber with :emperature control determines the loop operating temperature and the other compensation chamber will be liquid filled. The locp temperature can be controiled regardless of changes in the heat loads and/or sink temperatures to the extent that the set point temperature is higher than the naturally balanced temperature, i.e. the equilibrium temperature without heating the compensation chambers. When both compensation chambers are actively controlled to the same sei point temperature, control of the loop operating temperature can still shift from one compensation chamber to the other as heat load distribution changes. Basically, each compensation chamber heater is turned on or off according to its control band of the set point. Because of practical limitations, it is inpossible to have both compensation chambers controlled at an identical temperature. A slight temperature difference will generate enough pressure difference to cause one of the compensation chambers to be liquid-filled.

Test results in some tests indicate that both compensation chambers (at least both evaporator cores) contain two-phase fluid because the shift of operating temperature control was usually very smooth and no boiling was seen as in the non-control cases described above. Moreover, the liquid-filled compensation chamber could remain liquid filled until a drastic change is heat loads was made. Figure 8A shows the loop temperatures when both compensation chambers ware controlled at $308 \mathrm{~K}$ while the heat loads changed as follows: $100 \mathrm{~W} / 0 \mathrm{~W}, 75 \mathrm{~W} / 25 \mathrm{~W}, 50 \mathrm{~W} / 50 \mathrm{~W}, 25 \mathrm{~W} / 75 \mathrm{~W}$, and $0 \mathrm{~W} / 100 \mathrm{~W}$. Figures $8 \mathrm{~B}$ and $8 \mathrm{C}$ show the corresponding temperatures for $\mathrm{CCl}$ and $\mathrm{CC} 2$, respectively. The loop operating temperature was controlled by $\mathrm{CC} 2$ at heat loads of $100 \mathrm{~W} / \mathrm{CW}$ and $75 \mathrm{~W} / 25 \mathrm{~W}$, and control shifted to $\mathrm{CCl}$ at $50 \mathrm{~W} / 50 \mathrm{~W}$, $25 \mathrm{~W} / 75 \mathrm{~W}$, and $0 \mathrm{~W} / 100 \mathrm{~W}$. Figure $8 \mathrm{~A}$ shows that the vapor line temperature TC23 followed the saturation temperature governed by $\mathrm{TC} 17$ or TC7, depending on the heat lcads. In Figures $8 \mathrm{~B}$ and $8 \mathrm{C}$, the $\mathrm{CC} \mathrm{I}$ and CC2 temperature were uniform when controlling the ioop operating temferature, and scattered when liquid filled. Oscillations of $\mathrm{CCl}$ and $\mathrm{CC} 2$ temperatures were caused by the on/off cycle of the control heaters.

Figure 8. Power Cycle 10/5/00 data, $8: 45$ to $11: 00$. 
Figure 8A, TC7, 17, 10, 20, 2, 12, 23, E1, E2. (existing, should remove TC2, and TC12 for clarity)

Figure 8B, TC6, 7, 8, 9, EI, E2 (existing)

Figure $8 \mathrm{C}, \mathrm{TC} 16,17,18,19, \mathrm{E} 1, \mathrm{E} 2$ (existing)

Figure 9 shows the loop temperatures when the $\mathrm{CC}$ temperatures were cycled between $298 \mathrm{~K}$ and $308 \mathrm{~K}$ in the $(50 \mathrm{~W} / 50 \mathrm{~W}, 273 \mathrm{~K} / 273 \mathrm{~K})$ test. The loop operating temperature was controlled by $\mathrm{CCl}$ during the course of this test, and the vapor line temperature TC23 followed TC7. Although not shown here, CCI temperatures (TC6 to TC9) were uniform and CC2 temperatures (TC16 to TC19) spread more than 2 degrees.

Figure 9. Loop Temperatures in the (50W/50W, 27:K/273K) test where CC Temperature Varied Between $298 \mathrm{~K}$ and $308 \mathrm{~K}$.

10/13/00 data. Need 8:00 to 11:00 TC7, 17, 10,20, 23 (existing 9:50 to 13:00)

Capillary Limit

When the capillary limit of the primary wick in the LHP is exceeded, vapor will penetrated the primary wick and reach the evaporator core. Since the evaporator can tolerate vapor presence, the loop can continue to operate at a higher operating temperature [ ]. However, the vapor penetration will cause a rapid and large increase of the compensation chamber temperature. Thus, the capillary limit of the loop can be identified by a sudden and large increase of the loop operating temperature. The loop will reach another steady state if the capillary limit was not exceeded by too much at the moment of the vapor penetration. Since the surface tension of the working fluid is a function of the temperature, the capillary limit of the loop is also temperature dependent. In an LHP with multiple parallel evaporators, the pressure drop that each primary wick has to sustain depends on the total heat load as well as the heat load to that evaporator. Therefore, the heat transport limit is dependent upon the heat lcad distribution among all evaporators.

In the present test program, the capiliary limii was conducted using three different schemes: 1) heat load to a single evaporator only, 2) even heat loads to both evaporators, and 3) uneven heat loads to the two evaporators. Since El has a titanium wick that has a much lower capillary limit than the nickel wick used in E2, vapor penetration always occurted in El regardless of the heat load distributions. Figure 10 shows the loop temperatures when uneven heat loads were applied to both evaporators. The $\mathrm{Cl}$ and $\mathrm{C} 2$ sink temperatures were set at $163 \mathrm{~K}$ and $258 \mathrm{~K}$, respectively. The loop started with $0 \mathrm{~W} / 75 \mathrm{~W}$ (not shown in Figure 10 ), then E1/E2 heat loads increased to $0 \mathrm{~W} / 100 \mathrm{~W}, 0 \mathrm{~W} / 150 \mathrm{~W}$, and $0 \mathrm{~W} / 175 \mathrm{~W}$. Throughout the test, $\mathrm{CCl}$ controlled the loop operating temperature. Between $0 \mathrm{~W} / 75 \mathrm{~W}$ and $0 \mathrm{~W} / 125 \mathrm{~W}, \mathrm{CCl}$ temperature remained nearly constant at $297.5 \mathrm{~K}$. At $0 \mathrm{~W} / 150 \mathrm{~W}, \mathrm{CCl}$ temperature rose quickly to $307.5 \mathrm{~K}$, indicating that vapor penetration through El wick. Nevertheless, the loop reached a new steady state and continued to function. The loop reached a new and higher steady temiperature as the heat load was further increased to $0 \mathrm{~W} / 175 \mathrm{~W}$. The fluctuation of the El inlet temperature TC10 indicated that vapor was periodically injected into the El core. The heat load was then changed to $25 \mathrm{~W} / 150 \mathrm{~W}$. Even though $\mathrm{El}$ was subjected to a higher pressure drop at $25 \mathrm{~W} / 150 \mathrm{~W}$ than at $0 \mathrm{~W} / 175 \mathrm{~W}$, CCI temperature decreased because cold liquid was brought back to $\mathrm{CCl}$ to lower its temperature, as evidenced by the sudden drop of $E 1$ inlet temperature $\mathrm{TC} 10$. The $\mathrm{CCl}$ temperature dropped further as the heat load reduced to $25 \mathrm{~W} / 125 \mathrm{~W}$. However, E1 did not fully recover as the heat load reduced to $0 \mathrm{~W} / 125 \mathrm{~W}$. Periodic vapor penetration persisted. In fact, the operation at $0 \mathrm{~W} / 125 \mathrm{~W}$ looked more like the previous operation at $0 \mathrm{~W} / 150 \mathrm{~W}$. Only when the heat load reduced to $0 \mathrm{~W} / 100 \mathrm{~W}$ did the $\mathrm{El}$ wick fully recover.

Figure 10. Capillary limit with uneven heat loads.

$9 / 11 / 00,10: 30$ to $17: 00, \mathrm{TC} 7,17,10,20,2, \mathrm{E} 1, \mathrm{E} 2$.

Figure 11 shows the loop temperatures in the capillary limit test with even heat loads to the two evaporators and with both $\mathrm{CCI}$ and $\mathrm{CC} 2$ temperatures controlled at $303 \mathrm{~K}$. The $\mathrm{Cl}$ and $\mathrm{C} 2$ sink temperatures were set at $263 \mathrm{~K}$ and $258 \mathrm{~K}$, respectively. The heat load to each evaporator varied as follows: $25 \mathrm{~W}, 50 \mathrm{~W}, 60 \mathrm{~W}, 65 \mathrm{~W}, 70 \mathrm{~W}, 80 \mathrm{~W}, 85 \mathrm{~W}, 90 \mathrm{~W}, 65 \mathrm{~W}$, and $50 \mathrm{~W}$. The loop operating temperature was governed by $\mathrm{CC} 2$ temperature and $\mathrm{CCl}$ was subcooled for heat loads up to $65 \mathrm{~W} / 65 \mathrm{~W}$. As the heat load 
increased to $70 \mathrm{~W} / 70 \mathrm{~W}$, vapor penetrated the $E /$ wick and $C \mathrm{C}$ i tarperature rose above the set point temperature of $303 \mathrm{~K}$, controlling the loop operating teiriperature At each heat increase, $\mathrm{CCl}$ temperature increased to a higher steady tempcriture and $\mathrm{CC} 2$ became more subcocled. The $\mathrm{CCl}$ temperature increase with increasing heat load because more vapor penetrated through EI wick and the higher heat leak demanded a higher liquid subcooling which could not be achieved by the higher flow rate alone and must be compensated by a higher compensation chamber temperature. The El wick did not completely recover as the heat load reduced to $65 \mathrm{~W} / 65 \mathrm{~W}$ because the $\mathrm{CCl}$ termperature was still higher than the set point temperature. The El wick did recover as the heat load further reduced to $50 \mathrm{~W} / 50 \mathrm{~W}$. However, during the transient, the $\mathrm{CCl}$ temperature and hence the loop continued to drop below $303 \mathrm{~K}$ even though both $\mathrm{CCl}$ and $\mathrm{CC} 2$ heaters were cycled on. When $\mathrm{CCl}$ ternperature dropped to $295 \mathrm{~K}$, vapor bubbles were generated in CC2 and CC2 began to controlled the loop operating temperature at $303 \mathrm{~K}$, the set point of both compensation chambers. This represented a 8 degrees of superheat for boiling nucleation in $\mathrm{CC} 2$. The locp temperatures were similar to those at $50 \mathrm{~W} / 50 \mathrm{~W}$ prior to vapor penetration.

Figure 11. Capillary Limit with even heat loads.

10/19/00, 8:00 to 17:00, TC7, 17, 2, 12, 10, 20,23, E1, E2 (existing)

\section{Concluding Remarks}

An extensive test program was carried out for an LHP with two evaporators and two condensers. Tests performed include start-up, power cycle, sink temperature cycle, reservoir temperature cycle, and capillary' limit. The loop demonstrated very robist operation under various heat load and sink conditions.

The loop could start with heat loads to one or both evaporators. A sustaining back flow was observed in some tests during the pre-heating period of the compensation chambers. Low power start-up could still be problematic as with the LHP with a single evaporator. The loop operating temperature was a function of the total heat load, the heat load distribution between the two evaporators, temperatures of the two condenser sinks. Under most conditions, only one reservoir contained two-phase fluid and the other reservoir was comp!etely liquid filled. This is true even when both compensation chambers were actively control at the same temperature. Moreover, control of the loop operating temperature could shift from one compensation chamber to the other as the test condition changed. Nevertheless, the loop could adapt to the new test conditions even under fast transients.

\section{References}

1. Nikitkin, M., Birur, G. and j. Ku, “

2 Ku, J, "Operating Characteristics of Loop Heat Pipes," SAE Paper No. 1999-01-2007, $29^{\text {th }}$ International Conference on Ervironmental Systems, July 12-15, 1999, Denver Colorado.

3. Ku, J. and G. Birur, "An Experimental Study of the Operating Temperature in a Loop Heat Pipe with Two Evaporators and Two Condensers $31^{\text {st }}$ International Conference on Environmental Systems, July 9-12, 200, Orlando, Florida.

4. Ku, I. and G. Birur, "Active Control of the Operating Temperature in a Loop Heat Pipe with Two Evaporators and Two Condensers," $31^{\text {st }}$ International Conference on Environmental Systems, July 912,200 , Orlando, Florida.

5. Ku, J., Ottenstein, L., Rogers, P. and K. Cheing, "Low Power Operation of a Loop Heat Pipe," $31^{\text {s: }}$ International Conference on Environmental Systems, July 9-12, 200, Orlando, Florida. 


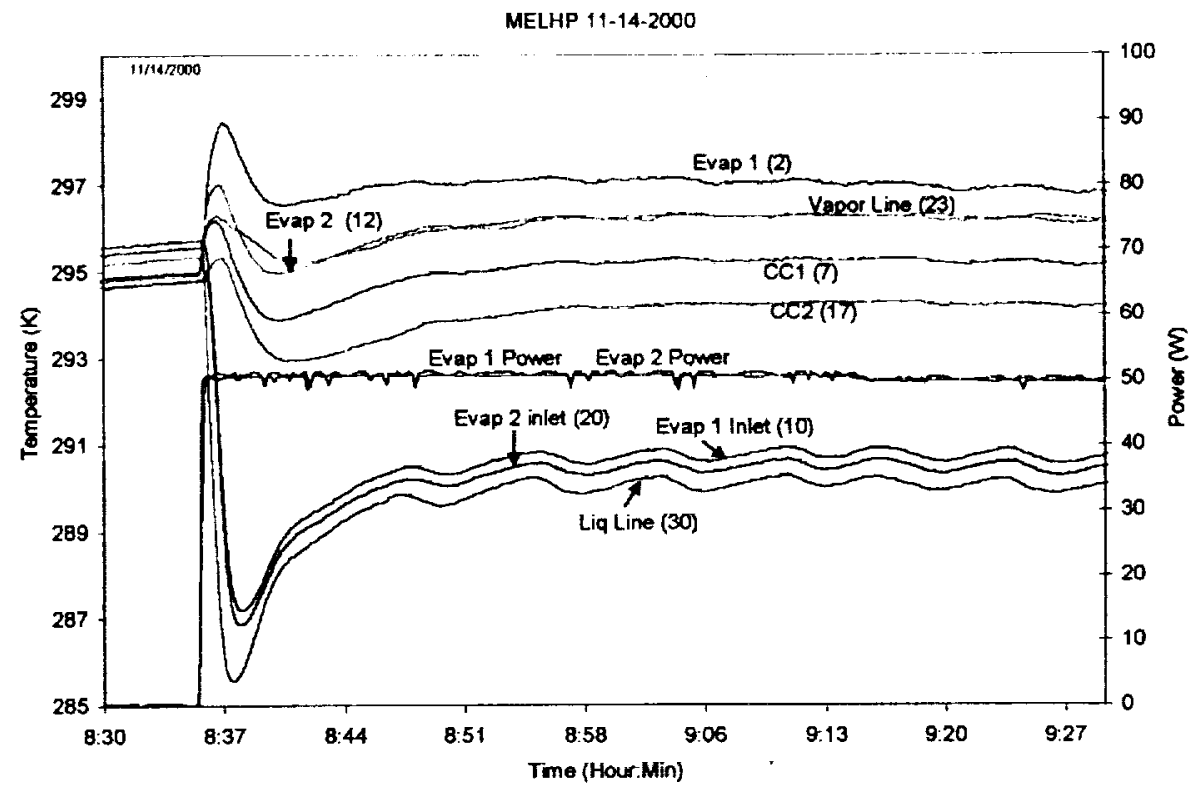

Figure 2. Loop Temperatures in the (50W/50W, 273K/273K) Start-up Test

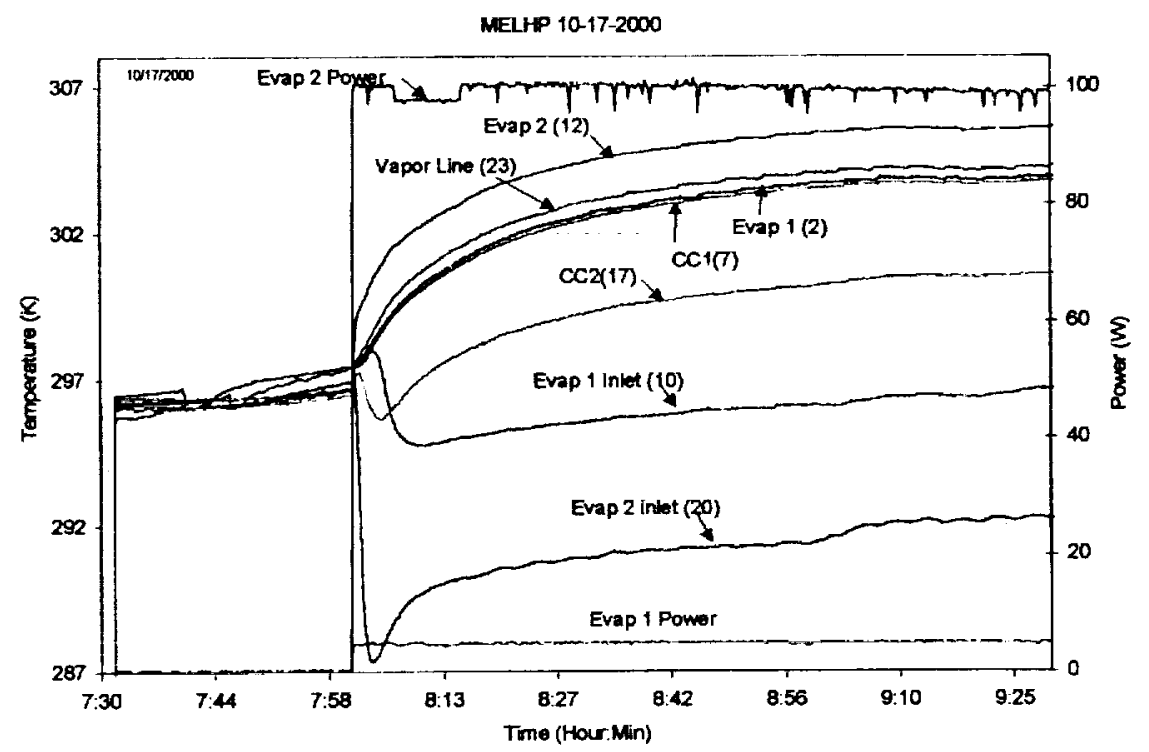

Figure 3. Loop Temperatures in the ( $5 \mathrm{~W} / 100 \mathrm{~W}, 273 \mathrm{~K} / 273 \mathrm{~K})$ Start-up Test 


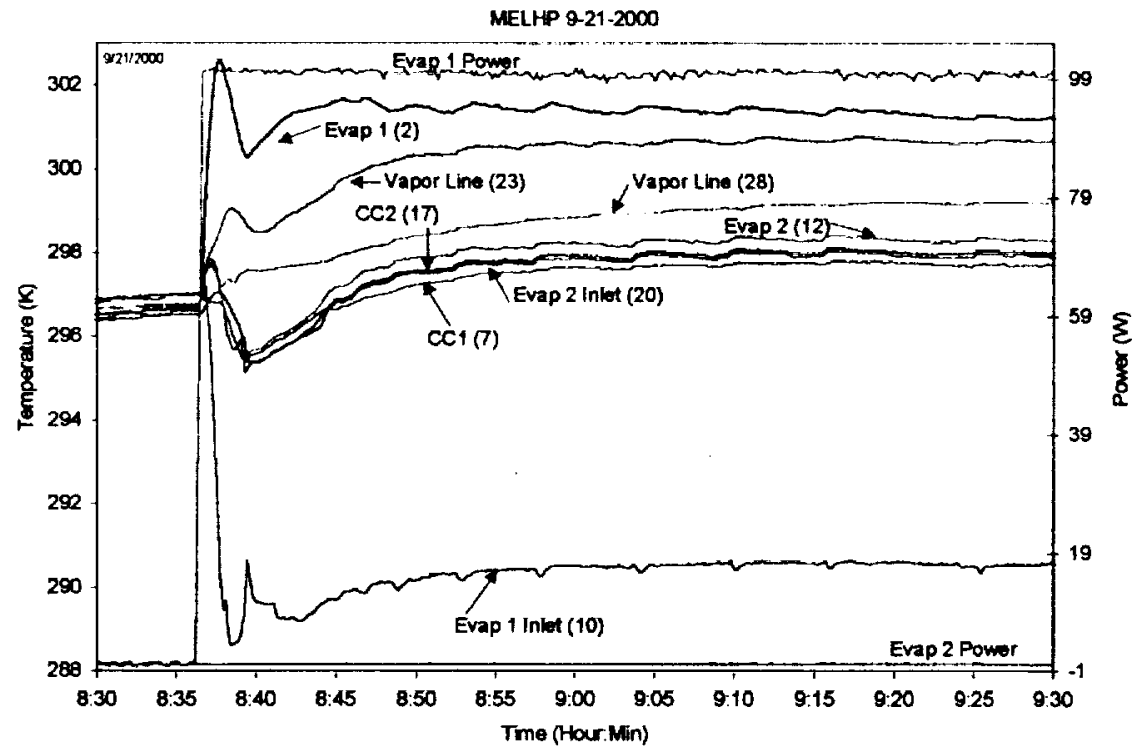

Figure 4. Loop Temperatures in the (5W/100W, 273K/273K) Start-up Test

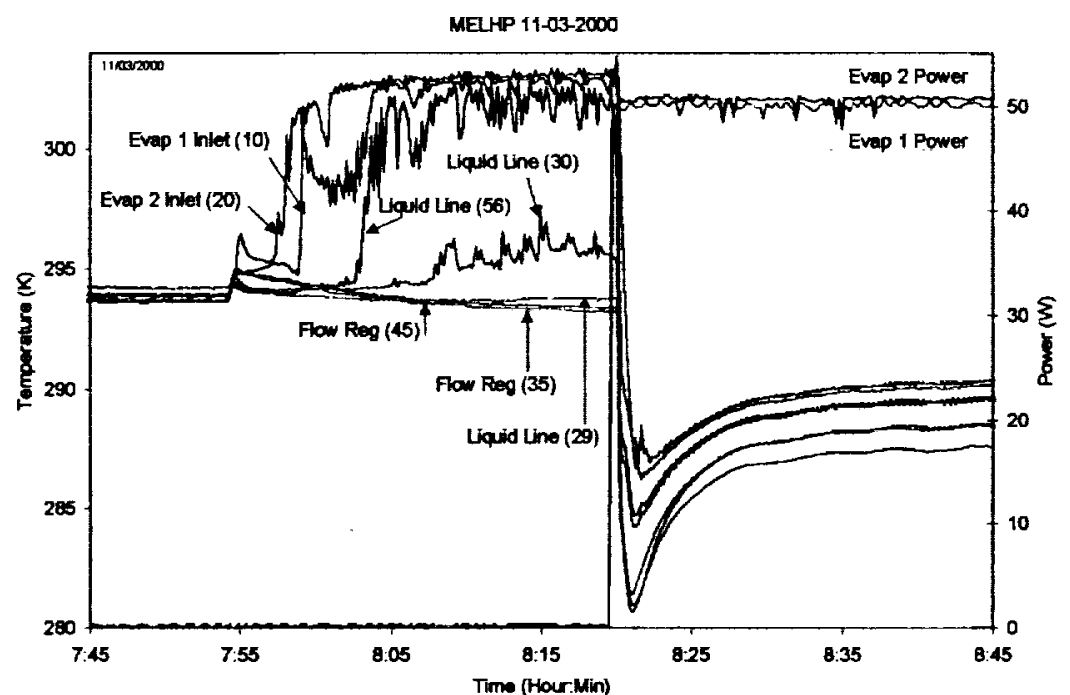

Figure 5. Start-up with Back Flow 


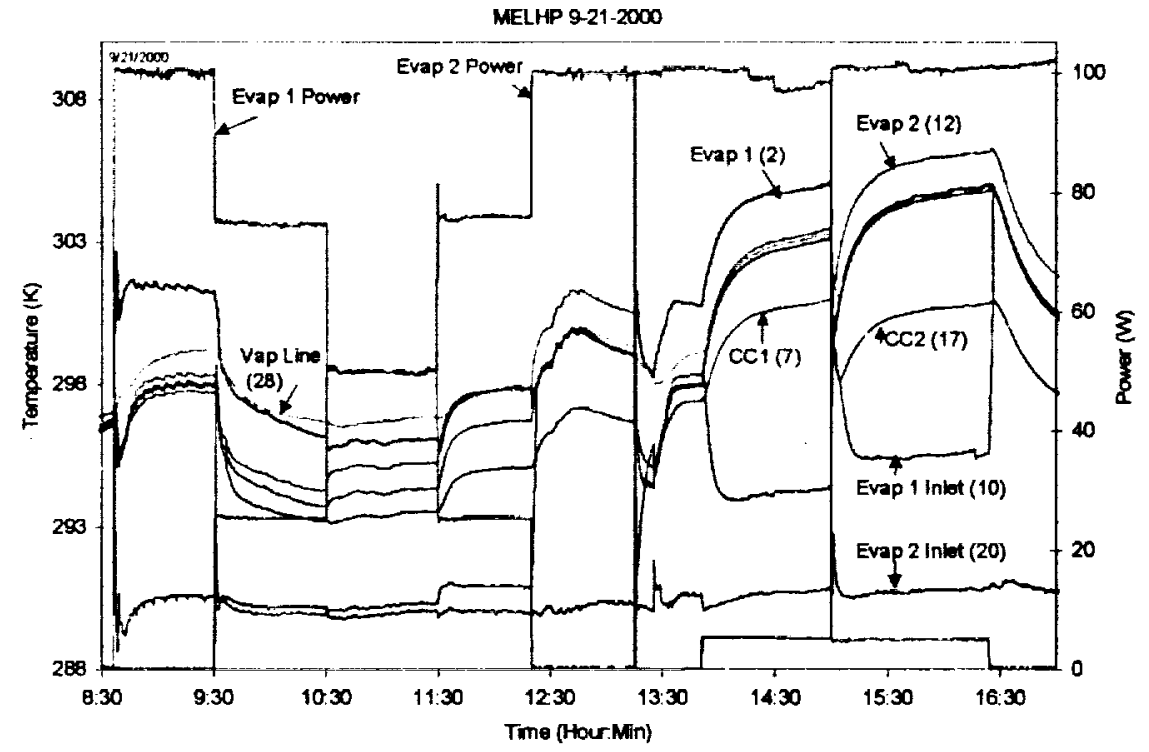

Figure 6A. Loop Temperatures in the Power Cycle Test

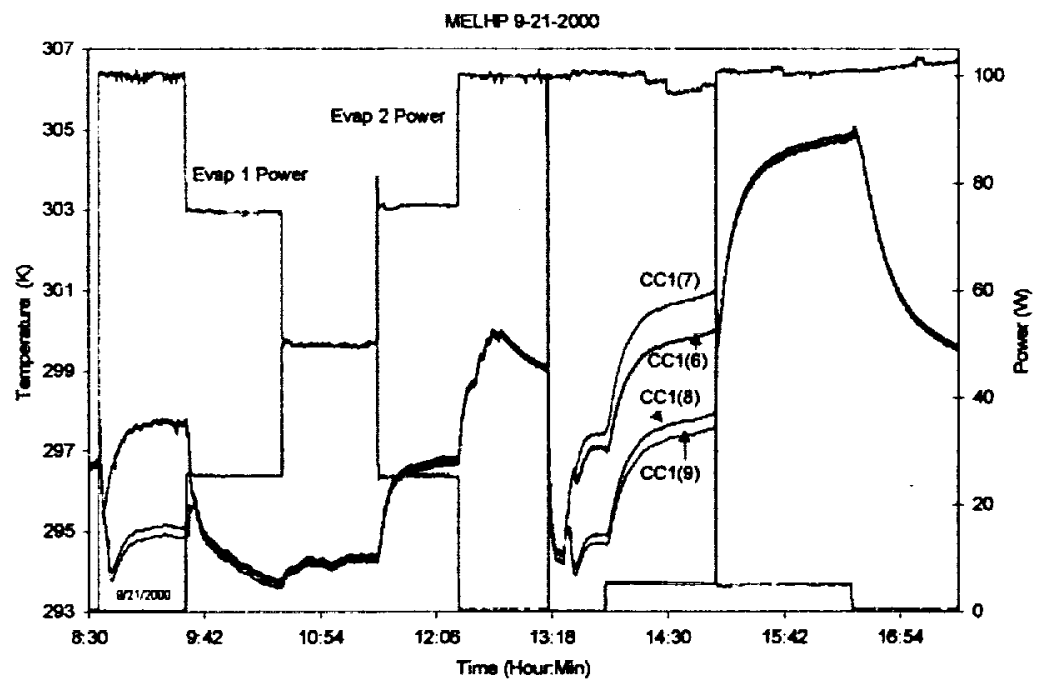

Figure 6B. CCI Temperatures in the Power Cycle Test 


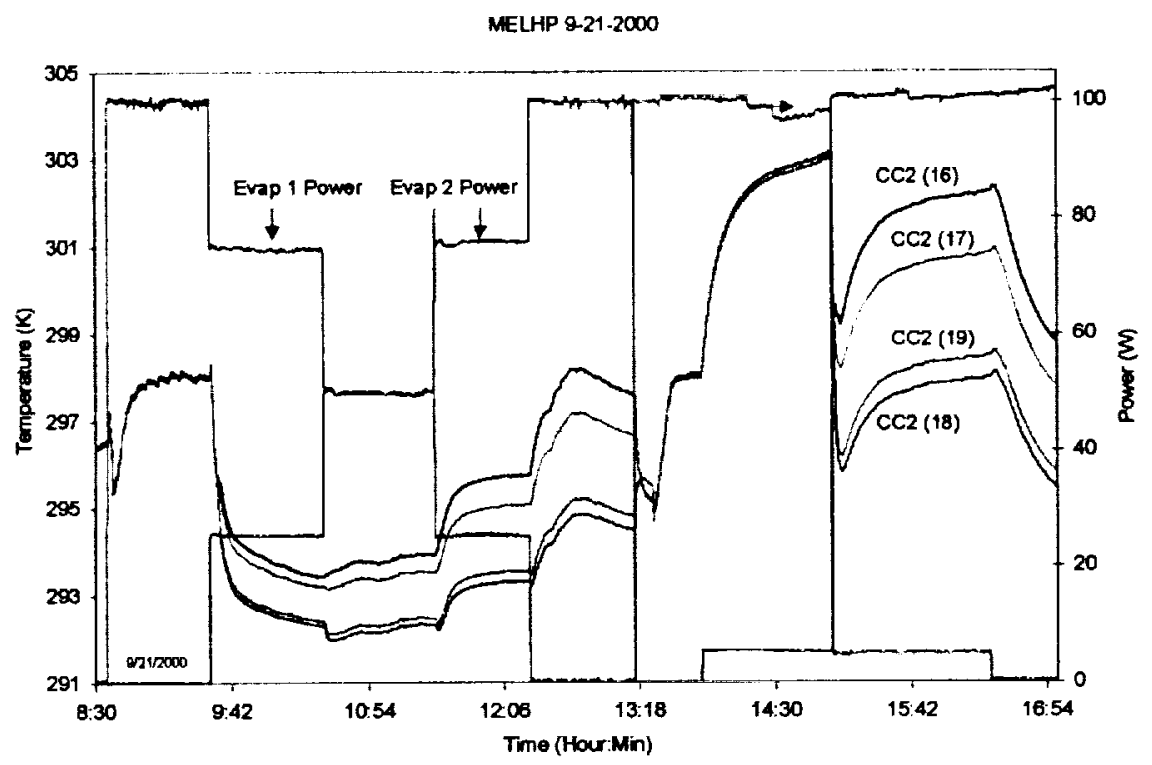

Figure 6C. CC2 Temperatures During Power Cycle Test

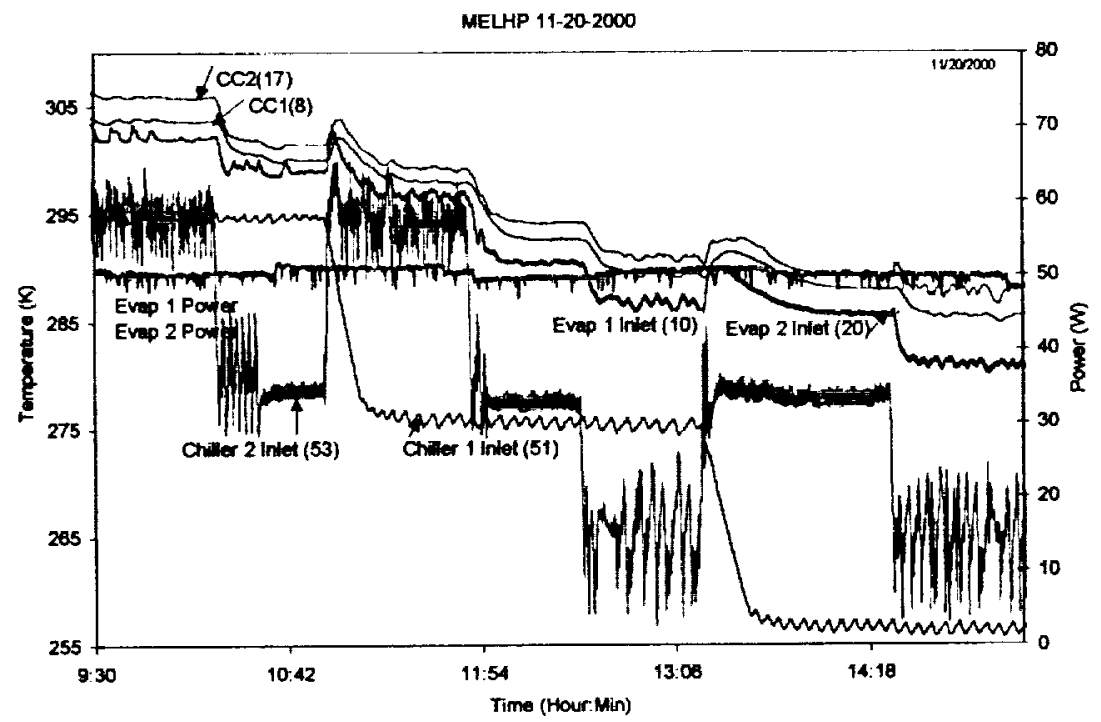

Figure 7. Loop Temperature During Sink Temperature Cycle Test 


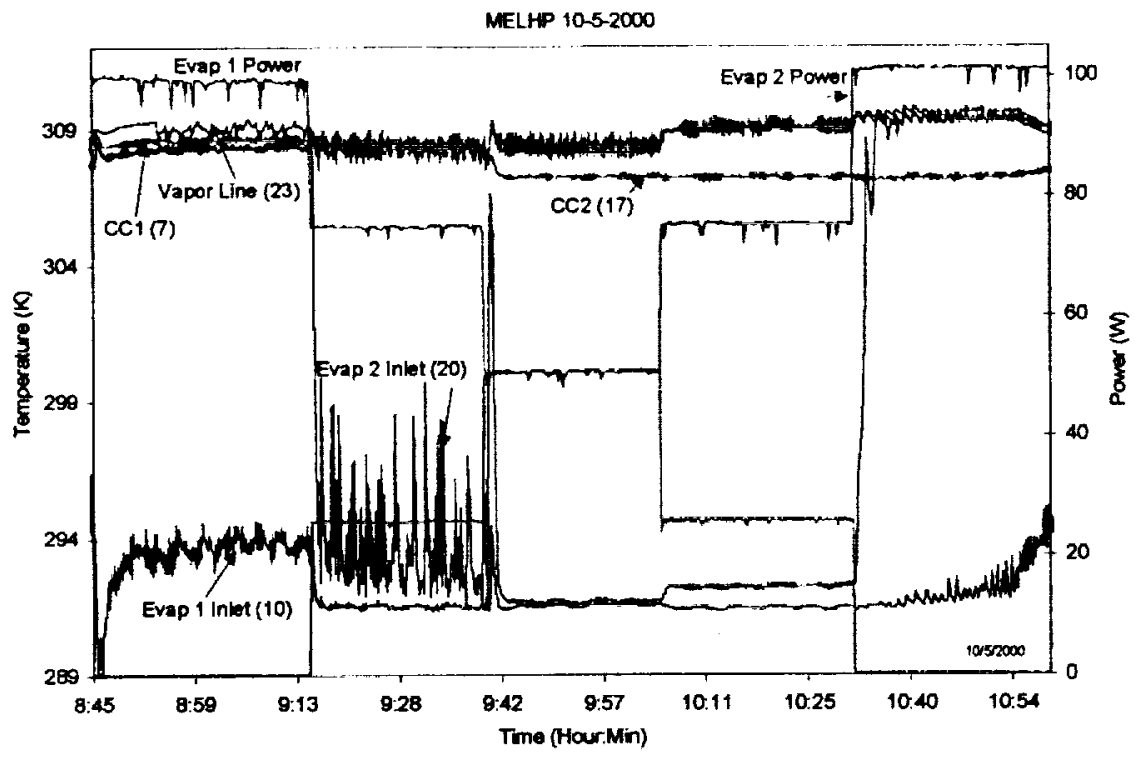

Figure 8A. Loop Temperatures During Power Cycle Test

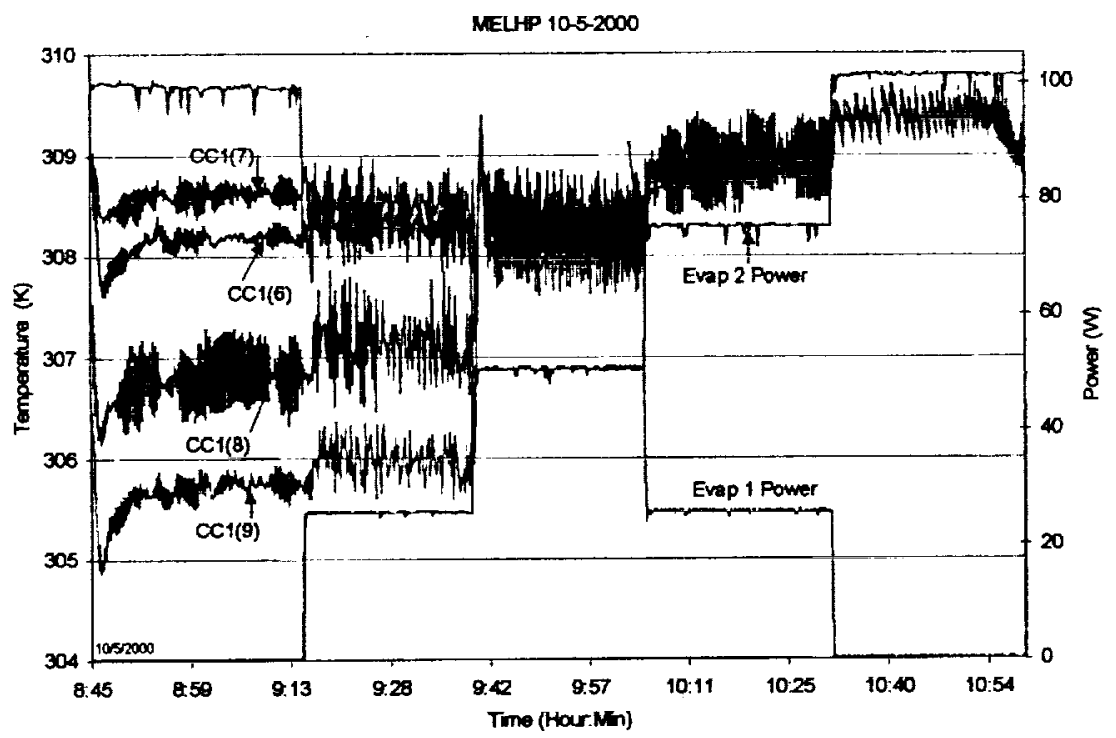

Figure 8B. CCl Temperature During Power Cycle Test 


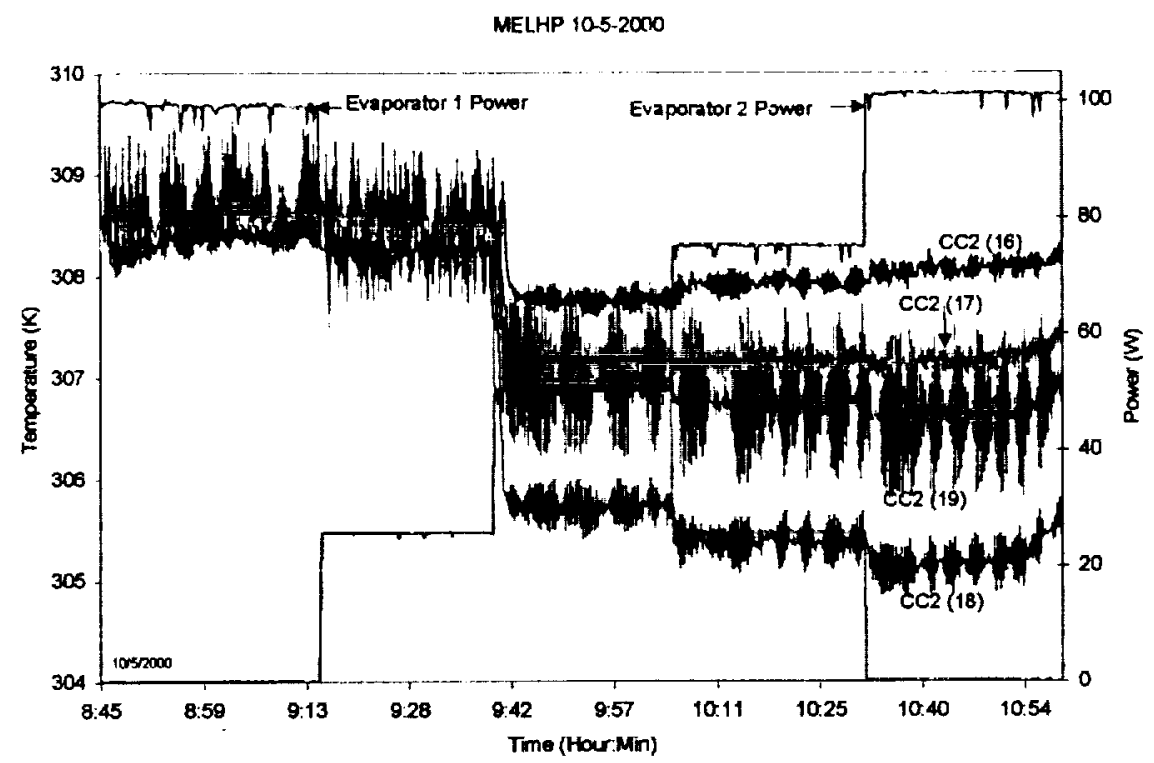

Figure 8C. CC2 Temperature During Power cycle Test

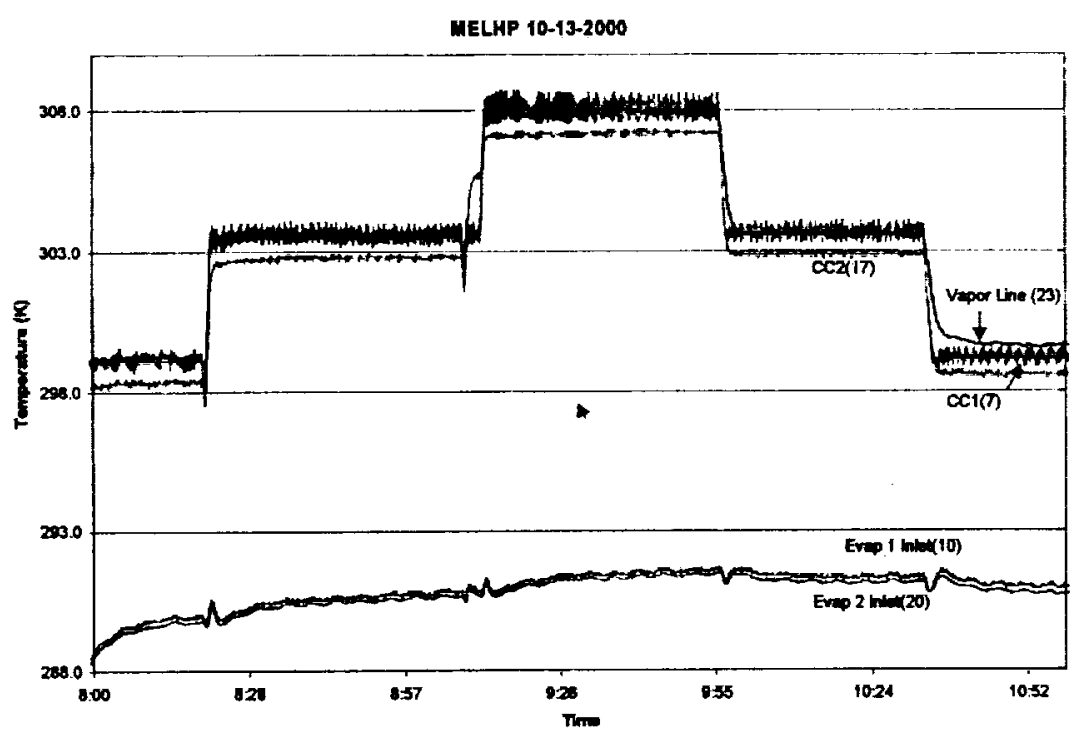

Figure 9. Loop Temperatures During Reservoir Temperature Cycle Test 


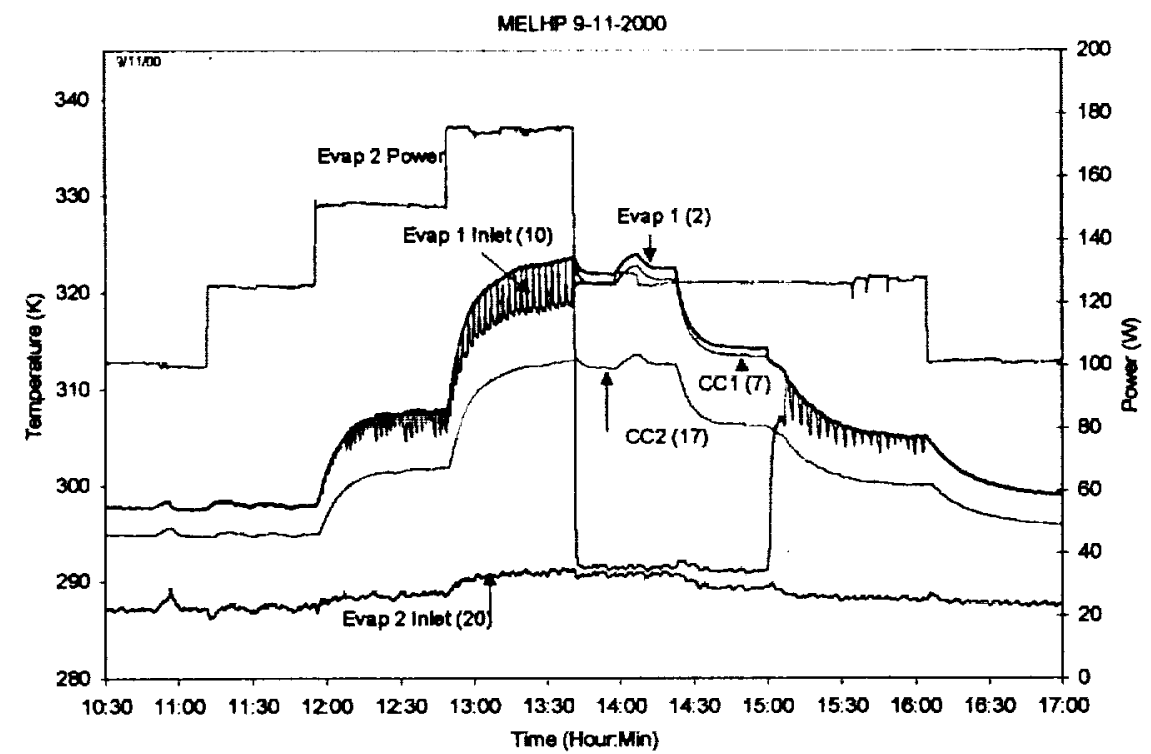

Figure 10. Loop Temperatures in Capillary Limit Test with Uneven Heat Loads

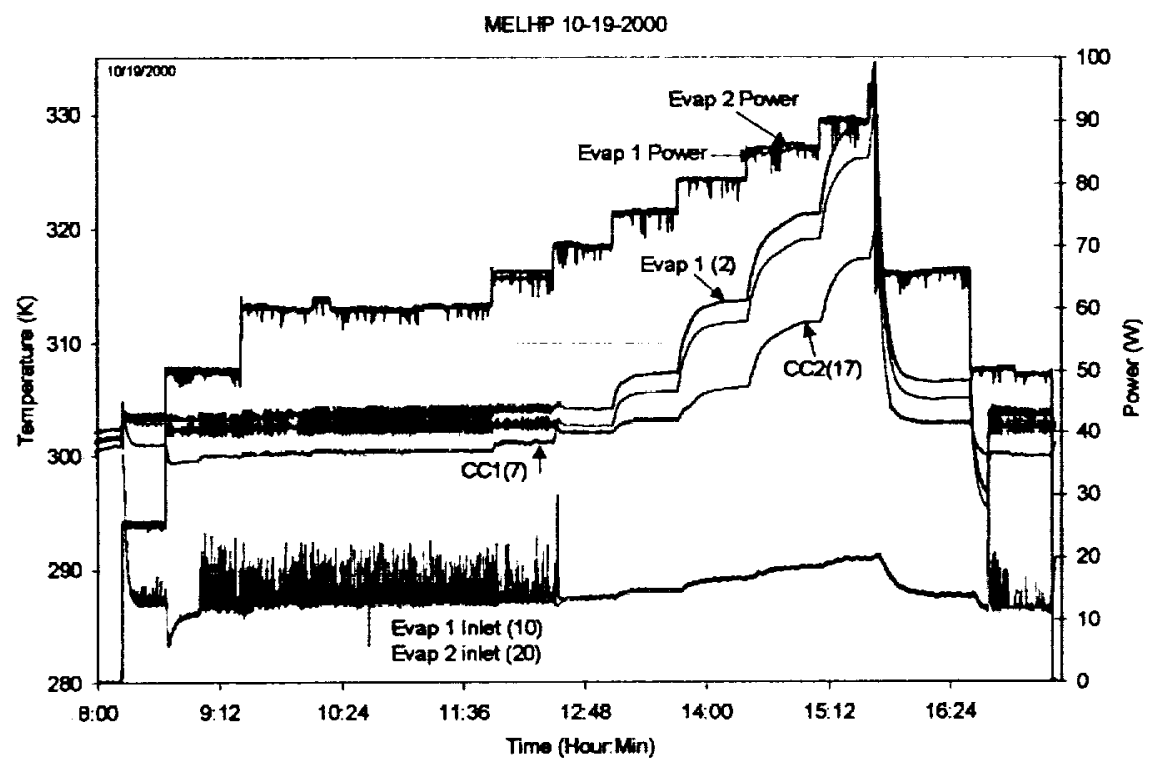

Figure 11. Loop Temperatures in Capillary Limit Test 